\title{
A reductase-mimicking thiourea organocatalyst incorporating a covalently bound NADH analogue: efficient 1,2-diketone reduction with in situ prosthetic group generation and recycling $\dagger$
}

\author{
Barbara Procuranti and Stephen J. Connon* \\ Received (in Cambridge, UK) 2nd January 2007, Accepted 4th January 2007 \\ First published as an Advance Article on the web 30th January 2007 \\ DOI: $10.1039 / \mathrm{b} 618792 \mathrm{~g}$
}

A new class of bifunctional organocatalyst promotes the chemoselective reduction of diketone electrophiles at catalytic loadings in the presence of an inorganic co-reductant.

Enzymatic manipulation of the NAD $(\mathrm{P})^{+} / \mathrm{NAD}(\mathrm{P}) \mathrm{H}$ redox couple in biotransformations is a fundamental competency common to all living cells. ${ }^{1}$ In biological systems levels of these cofactors are maintained through both continual degradation/biosynthesis ${ }^{2}$ and the coupling of oxidation/reduction reactions to sustain a redox balance. ${ }^{1,2}$ A considerable difficulty associated with the exploitation of biocatalytic reduction in preparative chemistry has been the need for the use of stoichiometric quantities of the expensive and significantly unstable (in solution) NADH cofactor. In response to this challenge several approaches to cofactor regeneration in preparative biooxidations/reductions ${ }^{3}$ have been developed, the most practical of which involve either a single (A, Fig. 1$)^{4}$ or binary (B, Fig. 1 $)^{5}$ enzyme system using either isolated enzymes or whole cells.

The excellent activity/selectivity of enzymatic reductase systems has inspired the development of de-novo designed small organic molecules for biomimetic reduction which can be categorised as being either chiral nicotinamide-based reagents ${ }^{6}$ or chiral NADHanalogue dependant organocatalysts. ${ }^{7-9}$ Benchmark systems in the former category of NADH model are reagents, capable of effecting highly enantioselective reduction of activated ketones at stoichiometric loadings in the presence of $\mathrm{Mg}^{2+}$ ions $(100 \mathrm{~mol} \%$ ) and are not regenerated, while the second class of reductase mimic can promote efficient reductions of $\alpha, \beta$-unsaturated electrophiles ${ }^{7-9}$ and imines ${ }^{10}$ with impressive levels of stereoinduction at catalytic loadings $(1-20 \mathrm{~mol} \%)$ in the presence of

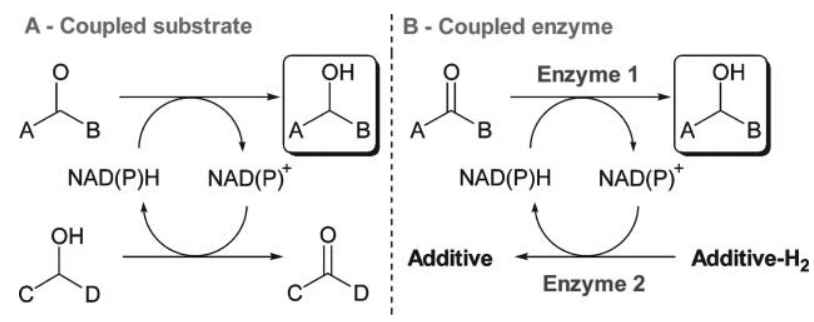

Fig. 1 Biocatalytic strategies for cofactor regeneration.

Centre for Synthesis and Chemical Biology, School of Chemistry, University of Dublin, Trinity College, Dublin 2, Ireland.

E-mail: connons@tcd.ie; Fax: +35316712826; Tel: +35316081306

$\dagger$ Electronic supplementary information (ESI) available: Synthesis of 10a, general reduction procedure and characterisation data for 2 and 18-23. See DOI: $10.1039 / \mathrm{b} 618792 \mathrm{~g}$ stoichiometric loadings of an achiral Hantzsch dihydropyridine hydride donor.

We have been engaged in the design of (thio)urea based bifunctional catalysts capable of activating electrophilic reaction components through hydrogen bond donation ${ }^{11}$ and were intrigued by the possibility of extending this strategy to include organocatalytic reductions. ${ }^{12}$ In particular, the development of a completely new class of bifunctional organocatalyst incorporating both a substrate-activating (thio)urea moiety and an organic hydride donor (as opposed to a binary catalyst system, e.g. Hantzsch ester and $\mathrm{Mg}^{2+}$ /organocatalyst) was appealing due to the increased potential for synergistic cooperation between the catalyst's functional components and for an increased measure of control (in a catalyst design context) over the catalyst-substrate interaction. To make the proposed process veritably catalytic in all organic components we also undertook to develop a conceptually novel artificial reductase system in which a NADH-model hydride donor could be both generated and recycled in situ by simple, chemical means.

With this in mind we prepared (thio)ureas 3-11 and evaluated their performance as promoters of the hitherto unknown (in an organocatalytic context) reduction of benzil (1) to benzoin $(2)^{13}$ in both the presence and absence (as appropriate) of substoichiometric amounts of $N$-benzylnicotinamide (BNA) in a biphasic aqueous/organic solvent medium (Table 1). The readily available and inexpensive sodium dithionate (a standard reductant for the preparation of 1,4-dihydropyridines from alkyl pyridinium salts) was assessed as a co-reductant for 'cofactor' generation/recycling. Surprisingly, a slow (inefficient) background reduction of $\mathbf{1}$ by the dithionite was observed at room temperature (Table 1 , entry 1). ${ }^{14}$ While the introduction of BNA $(20 \mathrm{~mol} \%$ ) resulted in marginally higher conversion (entry 2), the use of BNA in combination with bis- $N$-aryl(thio)ureas $\quad 3-6$ and 1,2-trans-diaminocyclohexanederived (thio)ureas 7-8 led to substantial improvements in reaction rate and efficiency (entries 3-6 and 8-9). Gratifyingly, the most efficacious promoters of the reaction proved to be bifunctional thiourea-based pyridinium salt precatalysts $\mathbf{1 0 a}, \mathbf{b}$, the most active of which was capable of bringing about the clean and chemoselective $^{15}$ reduction of $\mathbf{1}$ in $48 \mathrm{~h}$. The clear superiority of 10a,b over both their neutral (non-benzylated) precatalyst analogue 11 and BNA itself (entries 2, 11, 12 and 13) clearly indicates that $\mathbf{1 0 a}, \mathbf{b}$ operate primarily via a bifunctional reduction mechanism, i.e. intramolecular hydride donation from the in situgenerated hydropyridine moiety to the (thio)urea-bound diketone - and not (thio)urea-catalysed reduction of $\mathbf{1}$ by dithionate. This hypothesis is supported by the presence of the reduced form of 
Table 1 Preliminary catalyst evaluation
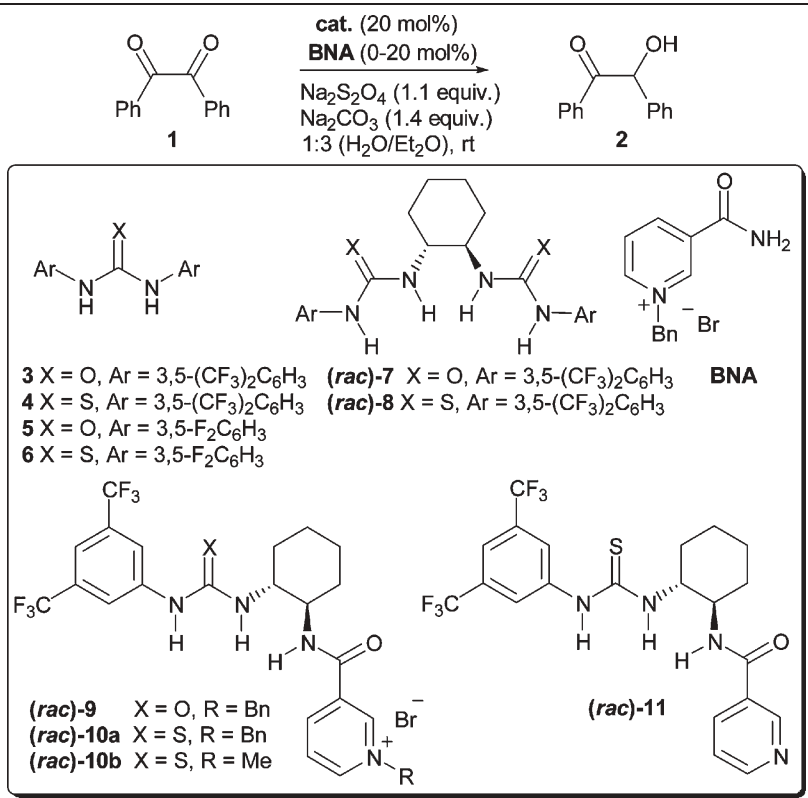

\begin{tabular}{llccc}
\hline Entry & Catalyst & mol $\%$ BNA & $t /$ h & Conv. $^{a}(\%)$ \\
\hline 1 & - & 0 & 48 & 6 \\
2 & - & 20 & 48 & 13 \\
3 & $\mathbf{3}$ & 20 & 48 & 35 \\
4 & $\mathbf{4}$ & 20 & 48 & 40 \\
5 & $\mathbf{5}$ & 20 & 48 & 29 \\
6 & $\mathbf{6}$ & 20 & 48 & 36 \\
7 & $\mathbf{3}$ & 0 & 48 & 12 \\
8 & 7 & 20 & 48 & 40 \\
9 & $\mathbf{8}$ & 20 & 48 & 21 \\
10 & $\mathbf{9}$ & 0 & 48 & 30 \\
11 & $\mathbf{1 0 a}$ & 0 & 48 & 71 \\
12 & $\mathbf{1 0 b}$ & 0 & 48 & 97 \\
13 & $\mathbf{1 1}$ & 0 & 48 & 8 \\
${ }^{a}$ Determined by ${ }^{1}$ H NMR spectroscopy. & \\
\hline
\end{tabular}

BNA as the only heterocyclic species observable (by ${ }^{1} \mathrm{H}$ NMR spectroscopy) in the organic phase of the reduction of $\mathbf{1}$ by BNA (Fig. 2 and Table 1, entry 2).

Further experimentation demonstrated that $\mathbf{1 0 b}$ is also effective in the reduction of a range of substituted benzils (1 and 12-17) of

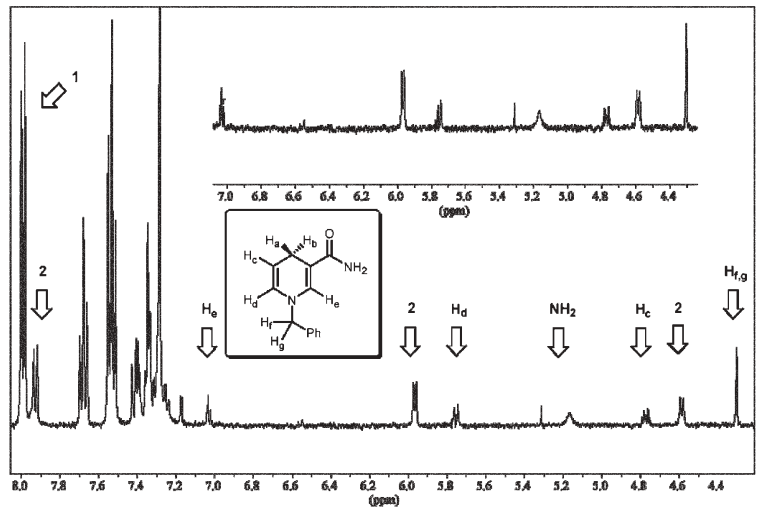

Fig. 2 Reduction of 1 by BNA in the presence of dithionate $(t=24 \mathrm{~h})$ : detection of the hydropyridine form of BNA by ${ }^{1} \mathrm{H}$ NMR spectroscopy. variable steric and electronic characteristics to the corresponding benzoins $\mathbf{2}$ and 18-23 in good to excellent yield at room temperature (Table 2). As expected, diketones bearing electron withdrawing substituents underwent faster reduction than less electrophilic analogues. ${ }^{16}$ Of particular interest is the use of this methodology in the synthesis of unsymmetrical hydroxyketones (entry 6) difficult to access in appreciable yield from the benzoin condensation of the corresponding aldehydes.

A preliminary investigation into the promotion of asymmetric reductions using enantiopure catalyst analogues was also undertaken. It was found that $(R, R)$-10a was capable of furnishing $(R)$-2 from 1 with moderate enantioselectivity (Scheme 1), however, evaluating the potential of the system is complicated by product racemisation under the reaction conditions. ${ }^{17}$

Table 2 Reaction scope

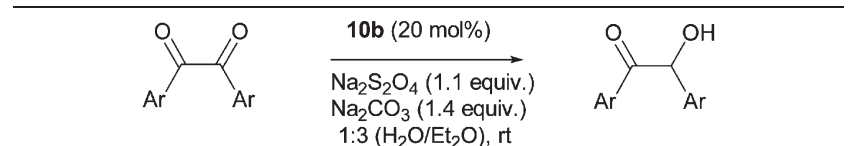

\begin{tabular}{llll}
\hline Entry Substrate & Product & $t / \mathrm{h} \quad \mathrm{Yield}^{a}(\%)$ \\
\hline
\end{tabular}

2
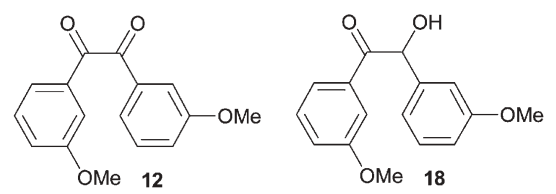

$48 \quad 96$

3

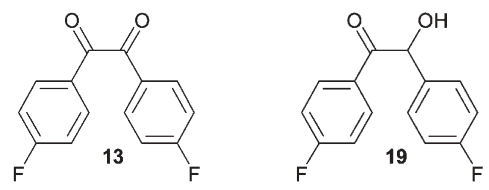

$48 \quad 77$

4

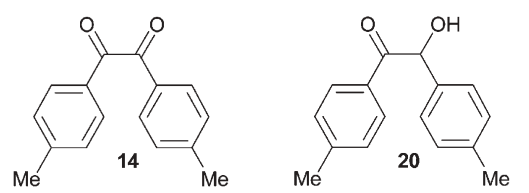

$7260^{b}$

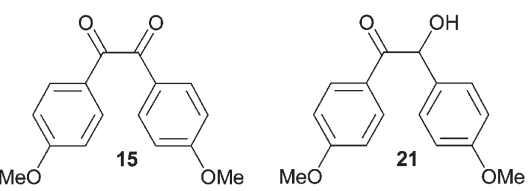

6
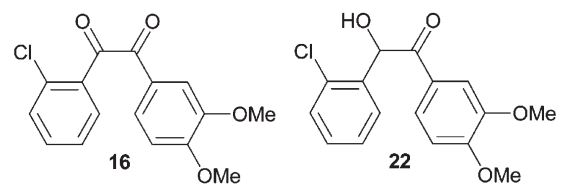

7
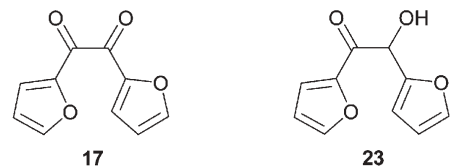

$96 \quad 72$

${ }^{a}$ Isolated yield after chromatography. ${ }^{b}$ Refers to conversion - no further conversion detected after extended reaction time. 


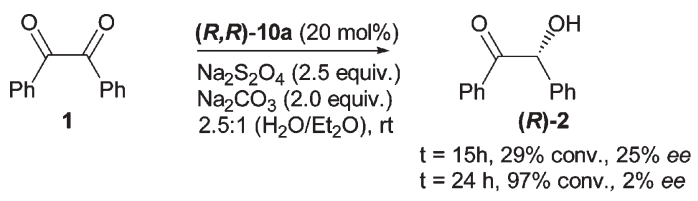

Scheme 1 Reduction using enantiopure $(R, R)-\mathbf{1 0 a}$.

In summary, we have developed the first class of thiourea-based bifunctional organocatalyst incorporating a chiral NADH analogue-component which can effect both the activation of and efficient hydride transfer to a 1,2-diketone electrophile at room temperature without the need for a stoichiometric Lewis-acidic $\left(\mathrm{Mg}^{2+}\right)$ additive. The precatalyst is readily prepared and the active hydropyridine catalytic species can be generated and recycled in situ using an inexpensive ${ }^{18}$ co-reductant, thus allowing the organic 'hydrogen source' to be employed at substoichiometric levels. ${ }^{19}$ Studies aimed at the expansion the reaction scope and the further development of analogous enantioselective systems are underway.

\section{Notes and references}

1 J. M. Berg, J. L. Tymoczko and L. Stryer, Biochemistry, Freeman, New York, 5th edn, 2002.

2 (a) M. Rechsteiner, D. Hillyard and B. M. Olivera, Nature, 1976, 259, 695; (b) M. Rechsteiner, D. Hillyard and B. M. Olivera, J. Cell Physiol., 1976, 88, 207; (c) D. Hillyard, M. Rechsteiner, P. Manlapaz-Ramos, J. S. Imperial, L. J. Cruz and B. M. Olivera, J. Biol. Chem., 1981, 256, 8491.

3 Selected recent reviews: (a) W. Kroutil, H. Mang, K. Edegger and K. Faber, Curr. Opin. Chem. Biol., 2004, 8, 120; (b) F. Hollmann and A. Schmid, Biocatal. Biotransform., 2004, 22, 63; (c) M. Eckstein, T. Daubmann and U. Kragl, Biocatal. Biotransform., 2004, 22, 89.

4 Selected references: (a) W. Stampfer, B. Kosjek, C. Moitzi and W. Kroutil, Angew. Chem., Int. Ed., 2002, 41, 1014; (b) M. Villela Filho, T. Stillger, M. Müller, A. Liese and C. Wandrey, Angew. Chem., Int. Ed., 2003, 42, 2993; (c) M. Eckstein, M. V. Filho, A. Liese and U. Kragl, Chem. Commun., 2004, 1084; (d) W. Stampfer, K. Edegger, B. Kosjek, K. Faber and W. Kroutil, Adv. Synth. Catal., 2004, 346, 57.

5 Selected references: (a) C.-H. Wong and G. M. Whitesides, J. Am. Chem. Soc., 1981, 103, 4890; (b) C.-H. Wong, D. G. Drueckhammer and H. M. Sweers, J. Am. Chem. Soc., 1985, 107, 4028; (c) H. Gröger, W. Hummel, C. Rollmann, F. Chamouleau, H. Husken, H. Werner, C. Wunderlich, K. Abotkitse, K. Drauz and S. Bucholz, Tetrahedron, 2004, 60, 333; (d) V. J. Shorrock, M. Chartrain and J. M. Woodley, Tetrahedron, 2004, 60, 781; (e) J. Zhang, B. Witholt and Z. Li, Chem. Commun., 2006, 398; (f) J. Zhang, B. Witholt and Z. Li, Adv. Synth. Catal., 2006, 348, 429.

6 (a) Y. Ohnishi, M. Kagami and A. Ohno, J. Am. Chem. Soc., 1975, 97, 4766; (b) T. Endo, Y. Hayashi and M. Okawara, Chem. Lett., 1977, 6, 391; (c) J. G. de Vries and R. M. Kellog, J. Am. Chem. Soc., 1979, 101, 2759; (d) A. Ohno, M. Ikeguchi, T. Kimura and S. Oka, J. Am. Chem. Soc., 1979, 101, 7036; (e) P. Jouin, C. B. Troostwijk and R. M. Kellog, J. Am. Chem. Soc., 1981, 103, 2091; (f) A. Ohno, J. Nakai, K. Nakamura, T. Goto and S. Oka, Bull. Chem. Soc. Jpn., 1981, 54, 3482; $(g)$ M. Seki, N. Baba, J. Oda and Y. Inouye, J. Am. Chem. Soc., 1981, 103, 4613; (h) M. Seki, N. Baba, J. Oda and Y. Inouye, J. Org. Chem., 1983, 48, 1370; (i) A. G. Talma, P. Jouin, J. G. de Vries, C. B. Troostwijk, G. H. Werumeus Buning, J. K. Waninge, J. Visscher and R. M. Kellog, J. Am. Chem. Soc., 1985, 107, 3981; (j) S. Yasui and A. Ohno, Bioorg. Chem., 1986, 14, 70; $(k)$ A. I. Meyers and T. Oppenlaender, J. Am. Chem. Soc., 1986, 108, 1989; (l) T. Imanishi, Y. Hamano, H. Yoshikawa and C. Iwata, J. Chem. Soc., Chem. Commun., 1988, 473; (m) V. A. Burgess, S. G. Savies and R. T. Skerlj, J. Chem. Soc., Chem. Commun., 1990, 1759; (n) V. A. Burgess, S. G. Savies, R. T. Skerlj and M. Whittaker, Tetrahedron: Asymmetry, 1992, 3, 871; (o) Y. Combret, J.-J. Torché, N. Plé, J. Duflos, G. Dupas,
J. Bourguignon and G. Quéguiner, Tetrahedron, 1991, 47, 9369; (p) Y. Combret, J. Duflos, G. Dupas, J. Bourguignon and G. Quéguiner, Tetrahedron, 1993, 49, 5237; (q) A. Ohno, A. Tsutsumi, Y. Kawai, N. Yamazaki, Y. Mikata and Y. Okamura, J. Am. Chem. Soc., 1994, 116, 8133; $(r)$ N. Kanomata and T. Nakata, Angew. Chem., Int. Ed. Engl., 1997, 36, 1207; (s) J. L. Vasse, P. Charpentier, V. Lavacher, G. Dupas, G. Quéguiner and J. Bourguignon, Synlett, 1998, 1144; $(t)$ N. Kanomata and T. Nakata, J. Am. Chem. Soc., 2000, 122, 4563; $(u)$ U. Gran, O. Wennerström and G. Westman, Tetrahedron: Asymmetry, 2000, 11, 3027; (v) Y. Mikata, K. Mizukami, K. Hayashi, S. Matsumoto, S. Yano, N. Yamazaki and A. Ohno, J. Org. Chem., 2001, 66, 1590; (w) R. Saito, S. Naruse, K. Takano, K. Fukuda, A. Katoh and Y. Inoue, Org. Lett., 2006, 8, 2067.

7 Overview: H. Adolfsson, Angew. Chem., Int. Ed., 2005, 44, 3340.

8 (a) J. W. Wang, M. T. Hechavarria Fonseca and B. List, Angew. Chem., Int. Ed., 2004, 43, 6660; (b) J. W. Wang, M. T. Hechavarria Fonseca, N. Vignola and B. List, Angew. Chem., Int. Ed., 2005, 44, 108; (c) S. G. Ouellet, J. B. Tuttle and D. W. C. MacMillan, J. Am. Chem. Soc., 2005, 127, 32; (d) J. W. Wang, M. T. Hechavarria Fonseca and B. List, J. Am. Chem. Soc., 2005, 127, 15036; (e) Y. Huang, A. M. Walji, C. H. Larsen and D. W. C. MacMaillan, J. Am. Chem. Soc., 2005, 127, 15051; (f) S. Mayer and B. List, Angew. Chem., Int. Ed., 2006, 45, 4193.

9 Uncatalysed reductions using a Hantzsch dihydropyridine: (a) S. J. Garden, C. R. W. Guimarães, B. Corréa, C. A. F. Oliveira, A. C. Pinto and R. B. Alencastro, J. Org. Chem., 2003, 68, 8815; (b) Z. Lui, B. Han, Q. Lui, W. Zhang, L. Yang, Z. L. Lui and W. Wu, Synlett, 2005, 1579.

10 (a) M. Rueping, E. Sugiono and T. Theissmann, Synlett, 2005, 2367; (b) M. Rueping, E. Sugiono, C. Azap, T. Theissmann and M. Bolte, Org. Lett., 2005, 7, 3781; (c) S. Hoffmann, A. M. Seayad and B. List, Angew. Chem., Int. Ed., 2005, 44, 7424; (d) R. I. Storer, D. E. Carrera, Y. Ni and D. W. C. MacMillan, J. Am. Chem. Soc., 2006, 128, 84; (e) M. Rueping, T. Thiessmann and A. P. Antonchick, Synlett, 2006, 1071; $(f)$ M. Rueping, A. P. Antonchick and T. Thiessmann, Angew. Chem., Int. Ed., 2006, 45, 3683.

11 Selected recent relevant reviews: (a) S. J. Connon, Chem.-Eur. J., 2006, 12, 5418; (b) M. S. Taylor and E. N. Jacobsen, Angew. Chem., Int. Ed., 2006, 45, 1520; (c) Y. Takemoto, Org. Biomol. Chem., 2005, 3, 4299; (d) A. Berkessel and H. Gröger, Asymmetric Organocatalysis, Wiley Interscience, Weinheim, 2005; (e) S. Jayasree and B. List, Org. Biomol. Chem., 2005, 3, 719; (f) P. M. Pihko, Angew. Chem., Int. Ed., 2004, 43, 2062; (g) P. R. Schreiner, Chem. Soc. Rev., 2003, 32, 289.

12 While this manuscript was in preparation, an excellent report concerning the first imine-transfer hydrogenation reaction to be catalysed by thiourea $\left(\mathrm{CH}_{4} \mathrm{~N}_{2} \mathrm{~S}\right)$ appeared: D. Menche, J. Hassfeld, J. Li, G. Menche, A. Ritter and S. Rudolf, Org. Lett., 2006, 8, 741.

13 Only one metal-based system has been reported to promote highly enantioselective asymmetric transfer hydrogenation of 1,2-diketones (benzil not tested): T. Koike, K. Murata and T. Ikariya, Org. Lett., 2000,2 , 3833. For a report on the difficulties associated with monoreduction of benzils, see: K. Murata, K. Okano, M. Miyagi, H. Iwane, R. Noyori and T. Ikariya, Org. Lett., 1999, 1, 1119. For a very recent example of metal-catalysed enantioselective reductions of $\alpha$-keto esters using stoichiometric loadings of a Hanztsch dihydropyridine, see: J. W. Yang and B. List, Org. Lett., 2006, 8, 5653.

14 Preparative reduction of benzil by $\mathrm{Na}_{2} \mathrm{~S}_{2} \mathrm{O}_{4}$ requires 3-4 equiv. of reductant and reflux temperatures in aqueous media: $(a) \mathrm{T}$. van Es and O. G. Backeberg, J. Chem. Soc., 1963, 1371; (b) S. M. Heilmann, J. K. Rasmussen and H. K. Smith, II, J. Org. Chem., 1983, 48, 987.

15 Reductions involving these catalysts (and the control reaction) were clean/chemoselective: no diols or other side products were detected.

16 Highly activated substrates such as aceanthrenequinone, 1-phenyl-1,2propanedione and methylphenylglyoxylate underwent fast reduction in the absence of catalyst.

17 This level of stereoinduction was reproducible over several experiments. When this reaction was repeated under the conditions used in Table 2 we detected (somewhat counter-intuitively) only racemic $\mathbf{2}$ at both 5 and $75 \%$ conversion.

$181 \mathrm{~kg}$ of sodium dithionite costs Stg $£ 17.60$ (Aldrich catalogue).

19 Note added in proof: after the original submission of this manuscript, a report concerning the efficient recycling of BNA in the ring-opening reduction of chalcone oxide appeared, see: H.-J. Xu, Y.-C. Liu, Y. Fu and Y.-D. Wu, Org. Lett., 2006, 8, 3449. 